\title{
DOES CRITICAL THINKING MEAN CULTURAL THINKING? USING LANGUAGE TO LEARN AND DEVELOP CHARACTER.
}

\author{
Tri Wahyuni Floriasti \\ Yogyakarta State University
}

\begin{abstract}
One of the most widely discussed concepts in education and educational reform these days is critical thinking. This thing we call critical thinking or analysis has strong cultural components. An area of cultural difference that may influence critical thinking is the use of language to effect thinking and learning. It is more than just a set of writing and thinking techniques- it is a voice, a stance, a relationship with texts and family members, friends, teachers, the media, even the history of one's country (Fox, 1994, p.125). Critical thinking begins when people make the connections between their individual lives and social conditions. In classrooms that feature critical thinking, students are encouraged to participate actively, raising issues of concern in their daily lives, such as work, school, and housing as topics for class discussion. As teachers and scholars grow to understand the unique characteristics of the culture, it is important to see, observe, analyze and response appropriately through language in the class and social life so that young generation can learn how to appreciate members of another culture and go hand in hand with them. It may become an effort to shape the civil society. This condition does not stop at that step. It leads them to act and response critically in daily life. Then, this beneficial actions form good characters.
\end{abstract}

Key words: Critical thinking, cultural thinking, language learn, character building

\section{INTRODUCTION}

Today, the world needs people with qualities of critical thinking to meet up the growing challenges; whereas, the education system in most of the countries is mere examination driven (Shiddiqui, 2007). The qualities of education and 
students' achievement are measured through statistically numbers. Indonesia needs more qualified people. Does Indonesia implement critical thinking in improving the higher order thinking critically?

In the United Stated, critical thinking (CT) movement has been going on for three decades (Rybold, 2010 and Nikoopour, et.al., 2011). California, in its landmark 1987 legislation, revamped education to require teaching of CT in all grades and made $\mathrm{CT}$ a compulsory general education requirement for all California community college and university graduates (Feare, 1992). This movement has fostered a proliferation of research, websites, and books to guide development of CT in reading, writing, and speaking (Rybold, 2010, p. 3). Critical thinking has been recently introduced and gained a high position in foreign language teaching (FLT) settings so that nowadays enhancing critical thinking in learners is considered one of the foreign language teachers' tasks (Shirkani \& Fahim, 2011, p. 1091). In teaching English as a foreign language, it is needed to be sensitive to the fragility of the students by using approach that promotes cultural understanding so that students can learn how to appreciate members of other cultures and go hand in hand with them. Meanwhile, learning English as a foreign language implies some degree of learning a second or foreign culture. Since language is a part of culture so students need to be aware of values in the society (Floriasti, 2012).

Therefore, what is critical thinking and how is critical thinking differ from thinking? What is the task for the language teachers? How to implement critical thinking in foreign language or second language teaching? Or does critical thinking mean cultural thinking, as L2 students are members of one society?

\section{DISCUSSION}

\section{What is critical thinking and how is critical thinking differ from thinking?}

Critical thinking refers to the individuals' ability to think and make correct decisions independently (Shirkani \& Fahim, 2011). Critical thinking or analysis is higher order thinking that occurs in social and daily life, and in academic environments. In other words, critical thinking is an everyday activity; whenever we want to make decision, we go through a thinking process (Nikoopour, et.al., 2011, p. 195). So, what is thinking? Does it different from critical thinking? How is critical thinking different from thinking? This table below can explain the focus, activity and goal of both thinking and critical thinking. 
Table 1. Thinking vs critical thinking

\begin{tabular}{|l|l|l|}
\hline & Thinking & Critical thinking \\
\hline Focus & $\begin{array}{l}\text { On information: data, } \\
\text { facts, examples } \\
\text { On ideas: Opinions, } \\
\text { positions }\end{array}$ & $\begin{array}{l}\text { On ideas: assumptions, } \\
\text { biases, flaws in reasoning, } \\
\text { point of view, context, } \\
\text { implications }\end{array}$ \\
\hline Activity & $\begin{array}{l}\text { Organizing and making } \\
\text { connections between } \\
\text { pieces of information or } \\
\text { ideas, sometimes making } \\
\text { basic inferences }\end{array}$ & $\begin{array}{l}\text { Deeply and broadly } \\
\text { questioning and testing the } \\
\text { ways in which an idea is } \\
\text { formed as well as how you } \\
\text { have been interpreting and } \\
\text { examining the idea. } \\
\text { Thinking about your own } \\
\text { thinking while you are } \\
\text { thinking about the thinking } \\
\text { of others. }\end{array}$ \\
\hline Goal & $\begin{array}{l}\text { To form an opinion about criteria in } \\
\text { what you are thinking } \\
\text { forming a conclusion or } \\
\text { evaluation about what you } \\
\text { have been thinking about } \\
\text { and how you have been } \\
\text { thinking about it }\end{array}$ \\
\hline
\end{tabular}

Source: http://ctl.utsc.utoronto.ca/twc/sites/default/files/criticalThinking.pdf

\section{What is the task for the language teachers? How to implement critical thinking in foreign language or second language teaching?}

Critical thinking matters in language learning, and demonstrates that English is regarded as an international language; there is a great need for its users and learners to be critical in their learning and using of the language. Shirkhani and Fahim (2010) state one of several reasons for promoting critical thinking in Foreign Language Teaching classroom is critical thinking has a high degree of correlation with learners achievements (Rafi, n.d.). Different investigations have confirmed the role of critical thinking. In a study conducted by Jodeiri, the relationship between the critical thinking ability and writing proficiency of intermediate Iranian EFL students was examined. The results indicated that there is a strong relationship between critical thinking ability and English writing skills of 
Iranian intermediate EFL learners. In fact, the higher the level of critical thinking of the participants, the more skillful their English writing ability will be.

Language development and thinking are closely related and the teaching of higher order thinking skills should be an integral part of an L2 curriculum. Lipman (2003) in Rafi says that it is responsibility of the teachers to develop critical thinking in the students other than pushing them from one educational level to the next. Brown (2004) proposes that the objectives of a curriculum in an ideal academic English program should go beyond linguistic factors, and to develop the art of critical thinking.

Teachers can increase students' critical thinking ability through the use of materials and types of activities. There are materials, which require the leaner to think critically if they want to develop critical thinking skills. For example materials can be analyzed, synthesized, discussed, argued about, classified in different ways are appropriate for this aim (Shirkani and Fahim, 2010). Consequently, the activities should be matched with the materials. Teachers need to apply such interactive activities as group work, project-based work, presentation, role-play, etc. In classrooms that feature critical thinking, students are encouraged to participate actively, raising issues of concern in their daily lives, such as work, school, and housing as topics for class discussion Benesch in Atkinson(1997, p. 545-548).

Critical reading activities provide opportunity for students to have critical thinking, creative and innovative character (Floriasti, 2011). Reading is a receptive activity. Critical reading is an evaluative activity while reading a text. There is an interaction between writers and readers intensively while reading. The writers express whatever idea to represent the aspired meaning and the readers figure the message. Careful readers try to interpret the meaning in the line or between the lines critically. They must be able to read in a critical way which means that they have to evaluate ideas once they understand them. Thus, readers know exactly the truth in text, the flows of the writers' idea and are confident to draw a conclusion. By reading critically, it is not only developing the ability to comprehend the message and draw conclusion, but also trigger critical thinking. It can be said that critical reading and critical thinking is born in the same time while the process of interaction is in progress between the writers and the readers everyday even they realise this condition or not. 
This condition does not stop at that step. It leads the readers to act and response critically in daily life. Then, this beneficial action forms good characters. Readers are no longer passive participants who take everything is written in the text, without questioning the ideas. They start judging and evaluating information critically, and decide to accept or refuse the writers' ideas.

What can the educators do in teaching reading especially critical reading? The following sections will help you sharpen your critical reading activities.

\section{Inferring Information}

When you found the main ideas in the preceding paragraphs, you were using inference. Making inferences is important in daily life. For example, if you see storm clouds, you might infer it will rain. Inference in reading is a type of informed guesswork in which the reader makes judgments about the author's meaning. You must read "between the lines." Sometimes you can correctly guess information that is implied in paragraph, but other inferences may not be supported by what the author has implied.

Information is not always stated in exact terms, we must supply our own information from details or ideas that are only suggested by the writer. We cannot always be certain that what we supply is absolutely right. But if we follow hunches that are based on evidence, we can be fairly sure about some things, even if they are only hinted at.

"If you find that you cannot easily answer a question about what you have read, remember to use inference skills. Return to the part of the reading where you expect the answers. Then see if the writer suggests something that you yourself have to supply in clearer terms" (Wiener \& Bazerman, 1988, pp. 155-156). Here are examples of inference activity for students.

\section{Making inferences}

Small group (3 students)

The following is one of Aesop's Fables, but it is presented without the ending, which you will have to figure out by using inference. 
1. Read the story and then answer the questions below.

An old lion, which was too weak to hunt or fight for his food, decided that he must get it by his wits. He lay down in a cave, pretending to be ill. Whenever any animals came to visit him, he seized them and ate them. When many had died in this way, a fox happened along. He stood at some distance from the entrance to the lion's den and inquired how the lion was feeling. "Bad", the lion answered, and asked the fox why he would not come inside the cave.

A. How does the fox know that the cave is a dangerous place?

B. Why is the fox sure that the lion will not come out and eat him?

C. What is a suitable moral for this story?

D. How do you suppose this story ends?

(Adapted from Wiener \& Bazerman, 1988, pp. 164-165)

2. Saudi Arabia Type : Individual

Instruction: If you can infer the statement from the paragraph, answer yes. If you cannot infer the statement, answer no. 
Saudi Arabia must import sand. This may seems strange, because most of the country is desert. But desert sand is too coarse to use in building. Building material must be fixed with fine sand to make strong cement blocks. It would be too expensive and too difficult to grind up the desert sand so that it could be used. Therefore, the Saudis must import river sand from Scotland.

1. Scottish sand is finer than Saudi Arabian sand.

2. Scottish sand is more useful for building than Saudi Arabia.

3. Sand is necessary in making cement.

4. The Saudis export their own sand to other countries.

5. Saudi Arabia has little or no river sand.

6. Saudi Arabia has no water.

(Taken from Minnette Lenier, 1991, p. 35)

\section{Evaluating Ideas}

Effective reading is more than just understanding. You must be able to read in a critical way which means that you have to evaluate ideas once you understand them. When you evaluate a writer's ideas, you judge the worth of what you read. "Here are some important questions to ask yourself in evaluating what you read.

- Does the author carefully separate objective fact from opinion?

- Does the passage present the facts completely, specifically, and accurately?

- Does the author seem reliable? Can you see what strengths or experiences make the author qualified to write about a topic?

- Does the author make any claims that seem outrageous or unsupportable?

- Does the author make his or her intent or point of view clear?

- Does the author take into account other points of view on the topic?

- Does the author try to appeal more to your emotions or to your reason and common sense? 
- Do your emotions get in the way of your ability to judge an author's statements fairly?

- Does it seem that the author is slanting information in such a way as to prejudice your ideas? Is the author using propaganda?

Here is an example of this activity.

\section{Finding out whose opinion is whose}

Work in pairs.

a. Sometimes a piece of writing will contain the opinion of people other than that of the writer. Read the following magazine editorial about perfume names.

b. Then match each opinion expressed in List A with the person who holds the opinion in List $B$. Write the letters of the names in List $B$ in front of the appropriate statements in List $A$. Names from List $B$ may be used more than once. Share it with your partner.

\section{NAME YOUR POISON}

A judge in Lausanne, Switzerland, has lifted a four-year-old ban on sales of a French perfume that goes by the name Opium. Advocates of the ban had argued that drug addicts hungry for a fix might mistake Opium for the real thing, thus doing themselves

injury. The judge found that line a bit overwrought, though allowing that the name showed "little socio-ethical taste". True, but Your Honour, when has taste ever interfered in the fashion and cosmetics industries? To be chic these days, a woman is expected to traffic in the pernicious and forbidden. The bikini, after all, was named after a harmless Pacific atoll whose fate was to be blown up by an H-bomb.

Bikinians must live with the knowledge that their home survives as synonym for a lady's swimsuit meant to devastate her man. At one time, scents were content with such darkly evocative labels as Taboo. Besides Opium, however, now we have a perfume called Poison. Charging a week's pay per ounce for a body dab named Poison must add up to one of the more perverse marketing decisions of recent years. But maybe it is a new trend. Why not a luxurious skin cream called 


\begin{tabular}{|c|c|c|}
\hline \multicolumn{2}{|c|}{ List A } & List B \\
\hline & $\begin{array}{l}\text { Drug addicts might mistake a } \\
\text { perfume for a drug. }\end{array}$ & $\begin{array}{l}\text { i. A judge in Switzerland } \\
\text { ii. }\end{array}$ \\
\hline & $\begin{array}{l}\text { Naming a perfume Poison is } \\
\text { perverse. }\end{array}$ & $\begin{array}{l}\text { iii. Advocates of the ban on sales of } \\
\text { Opium }\end{array}$ \\
\hline & Naming a perfume Opium is legal. & iv. The editorial writer \\
\hline & $\begin{array}{l}\text { Naming a bathing suit Bikini } \\
\text { might upset Bikinians. }\end{array}$ & \\
\hline & $\begin{array}{l}\text { To be fashionable, a woman } \\
\text { should deal with slightly } \\
\text { dangerous products. }\end{array}$ & \\
\hline & Perfume names show bad taste. & \\
\hline & $\begin{array}{l}\text { Perfumes with dangerous names } \\
\text { should sell well. }\end{array}$ & \\
\hline
\end{tabular}

(Adapted from Wiener \& Bazerman, 1988, pp. 204-205)

\section{Fact and Opinion}

"Most reading samples contain ideas based on fact and opinion. Of course it is not always easy to keep the two apart. A writer often combines the two in such a way that you do not always notice where fact ends and opinion begins... You want to be able to distinguish between two types of statements as you read.

Facts are statements that tell what really happened or really is the case. Afact is based on direct evidence. It is something known by actual experience or observation. Opinions are statements of belief, judgement, or feeling. They show what someone thinks about a subject. Solid opinions, of course, are based on facts. However, opinions are still somebody's point of view of something and are not facts themselves" (Wiener \& Bazerman, 1988, pp. 196-197).

It is important to distinguish between these two kinds of information so that you can use both to your advantage... Just because facts are reliable does not mean that they speak for themselves. Facts are significant only when they are used responsibly to support a claim; otherwise, a thoughtful and well-informed opinion might have more impact. To distinguish between fact and opinion, ask yourself 
questions about a statement you have read: Can it be proved? Can it be challenged? How often is the same result achieved? If a statement can consistently be proved true, then it is a fact. If it can be disputed, then it is an opinion.

The most knowledgeable people are those who realize that the line between fact and opinion is not always clear... Knowledgeable people, then, are constantly assimilating new information and questioning old ideas. Critical readers and thinkers are always prepared to interpret and assess the information before them; they evaluate the stance, the beliefs supporting such a stance, the kinds of sources used, and the objections that could be made. Careful writers and readers ask what kind of verification could establish the reliability of the information" (Glenn et al., 2004, pp. 502-503).

Here is an example of activities for distinguishing fact and opinion.

\section{Distinguishing fact and opinion 2}

Individually

1. Determine which of the following statements seem to be facts and which seem to be opinions.

2. In each case, what kind of verification would you require in order to accept the statement as reliable?

3. Explain your decisions in writing, and be prepared to discuss your choices in class.
A. Toni Morrison won the Nobel Prize in literature in 1993.
B. Women often earn less money than men holding the same positions.
C. The Lion King was the best movie ever made about animals.
D. Writing well is a gift, like musical genius.
E. A university degree guarantees a good job.
F. The oldest city in the United States is Santa Fe.
G. Running is good for your health.
H. The United States won the Second World War.
I. In combination, ammonia and chlorine bleach result in poisonous gas.
J. Researchers will find a cure for AIDS.

(Adapted from Glenn et al., 2004, p. 504) 


\section{Evidence}

Sometimes, when writers state their opinions, they just assert their points of view without providing any support. In such cases you have no particular reason to believe their opinions unless you trust them as authorities or experts. Any writer even an 'expert' who states opinions without giving supporting evidence probably should not convince you.

More often, writers will try to convince readers to share their opinions by presenting various facts or evidence, just as a lawyer presents evidence in a court case to support the opinion s that the accused is innocent or guilty of a crime. Just as a jury must evaluate the evidence carefully to decide whether to accept a lawyer's opinion about eh accused, so must you evaluate the evidence presented in what you read to decide whether to accept a writer's opinion. The following questions will help you to evaluate any evidence offered in support of an opinion you find express in your reading.

- Can the facts be trusted?

- Are the facts given in an objective way?

- Do the facts really support the opinion being expressed?

- Are the facts relevant to the point being made?

- Have unfavourable or negative points been left out?

- Do the facts prove the writer's opinion, or do they only suggest that the opinion is reasonable?

(Wiener \& Bazerman, 1988, p. 206).

Those sections above can give both educators and students extra help in comprehending meaning, judging and inspiring their actions and finally creating and producing something useful for students. In this step, students use their creativity and belief to response any information they get either from written or spoken text. 
Here is an example of the activity.

Man has been communicating by pictures longer than he has been using words. With the development of photography in this century we are using pictures as a means of communication to such an extent that in some areas they overshadow verbal language. The science of semantics has studied the conveyance of meaning by language in considerable detail. Yet very little is known as to how pictures convey meaning and what their place is in the life of man.

- Paul R Wendt
A. What is the main opinion expressed in this passage?
B. What evidence is given to support this opinion?
C. State one other opinion expressed in this passage.
D. What evidence is given to support this other opinion?
E. How well are the opinions in this passage supported by evidence?
F. What kind of evidence might make the opinions more convincing?

(Adapted from Wiener \& Bazerman, 1988, pp. 207-210)

\section{Does critical thinking mean cultural thinking?}

Other perception comes from Atkinson who states that critical thinking is social practice. Critical thinking begins when people make the connections between their individual lives and social conditions. In addition, social practices that have been done by the members of the society are influenced by the way they think and act in social interaction. This thing we call critical thinking or analysis has strong cultural components. An area of cultural difference that may influence critical thinking is the use of language to effect thinking and learning. It is more than just a set of writing and thinking techniques- it is a voice, a stance, a relationship with texts and family members, friends, teachers, the media, even the history of one's country (Fox, 1994, p.125).

What evidence exists, that critical thinking is more in the nature of a social practice than a well-explicated response in education? (Atkinson, 1997, p.73). Although some authors support universal principles in critical thinking (Paul, 2007), it is more relevant to discuss how thinking, in general, and systems of logic, specifically, are dependent on cultures (Rybold, 2010, p. 5). Nisbett (2003) in 
Rybold (2010) compared the cognitive tendencies that are embedded in cultural differences between the west and the east. He summarized some of these tendencies in thinking: Westerners attending more to object and Easterners more likely to detect relationships. In terms of use of formal logical rules, westerners are more inclined to use logical rules to understand events than Easterners.

Even within what is classified as the "west", cultural differences from the worldviews dictate different views of thinking. Gudykunst \& Kim (2003) in Rybold (2010) document that those in the US see the world in dichotomiessimplifying the view of the world, while Europeans are less reliant on facts, induction, and operationalism.

\section{CONCLUSION}

Critical thinking can be viewed in two points, as educational practice or as social practice. Both of them are intertwined in some roots. Teaching foreign language should take the local social context into account, which means learners' background influences the way they see, respond and think in L2. They cannot be separated from the way they were raised then it manifest in their thought in their L1. Does the way they think in L1 influence the way they think in L2, which can be seen from their production skill such as speaking?

For elementary and secondary teachers, it is you who can measure the need of your students in getting the critical thinking skills level. The things, which should not be left behind, are materials, activities, strategies, and media to support the way to reach critical thinking skills. Students' responses are the key to develop character building. Most people acquire language in the same way communication both written and spoken. In the process of communication, speakers know the rules how to communicate to others, and get information, knowledge about the language itself. In this point, they know how to get along with other people and appreciate different things. Then, they need to study hard because there is no magic powder to turn a "zero" person who does not have postulation of English into a well writtenspoken "hero" in one blink of eyes. Struggling and even falling into pieces are commonly seen in the process to become good students. This process describes how one character develops to another good character. The characters that can be listed from the explanation above are: creative, critical, innovative, responsible, hard working, discipline and so on. 


\section{REFERENCES}

Atkinson, Dwight. (1997). A Critical Approach to Critical Thinking in TESOL. TESOLQUARTERLY Vol. 31, No. 1 Spring 1997

Floriasti, Tri Wahyuni. "Developing Character building through multicultural reading text", Article in Conference Proceeding Presented at International Seminar ACLL Osaka, Japan, April 28, 2012

Floriasti, Tri Wahyuni. "Developing Character Building through Critical Reading”. Article in Conference Proceeding Presented at $58^{\text {th }}$ TEFLIN International Conference, IKIP PGRI Semarang, Indonesia, November 3$5,2011$.

Glenn, C. Miller, R. K., Webb, S. S., Gray, L. \& Hodges, J. C. (2004). Hodges' Harbrace Handbook. USA: Thomson Wadsworth.

Maker, Janet. Lenier, Minnette, (1991). College Reading Book. Third Edition. California:Wadsworth.

Nikoopour, Jahanbakhsh., Farsani, Mohammad Amini., Nasiri, Maryam. (2011).

On Relationship Between Critical Thinking and Language Learning Strategies Among Iranian EFL Learners. Journal of Education, Vol. 5, No. 3 Spring 2011.P. 195-200

Rybold, Gary. (2010). Speaking and Thinking: Understanding Oral Problem Solving Efficacy in Second Language Learners. Chinese Journal of Applied Linguistics (Bimonthly). Jun 2010, Vol33 No. 3

Rafi, Muhahhad Shaban. Promoting Critical Pedagogy in Language Education. International Research Journal of Arts \& Humanities (IRJAH) Vol. 37

Shirkhani, Servat., Fahim, Mansour. Enhancing Critical Thinking in Foreign Language Learners. Article presented in $1^{\text {st }}$ International Conference on Foreign Language Teaching and Applied Linguistics, May 5-7, 2011. Sarajevo.

Wiener, H. S. \& Bazerman, C. (1988). Reading skills handbook. (4th ed.). Boston: Houghton Mifflin.

http://ctl.utsc.utoronto.ca/twc/sites/default/files/criticalThinking.pdf 